Shao, X., Scherlen, A. (2007). Perceptions of Open Access publishing among academic journal editors in China. Serials Review, 33(2), 114-121 (ISSN 0098-7913) Published by Elsevier doi:10.1016/j.serrev.2007.02.002

\title{
Perceptions of Open Access Publishing among Academic Journal Editors in China
}

\author{
Xiaorong Shao and Allan Scherlen (Column Editor, "The Balance Point")
}

\begin{abstract}
Open access publishing is examined from the perspective of academic journal editors in mainland China, Hong Kong, and Taiwan. In addition to providing background information on academic publishing in China, the author incorporates interviews with two editors from open access and four from traditional subscription-based journals in the region. The editors share their general views on Chinese academic publishing and reflect on how open access has or could affect their publications. The editors comment on such issues as the economic viability of open access publishing in China and the potential benefits and challenges faced by Chinese academic journal editors who pursue open access.
\end{abstract}

\section{Column Editor's Introduction}

Interest in open access to scholarly communication has steadily expanded geographically in recent years throughout Europe and the Americas, and into other areas of the world, recently exemplified by the launching of SPARC Japan in December 2006. As China takes an increasingly important role in international scholarly publishing, the serials community outside China is interested not only in methods for extending delivery of their scholarly output to China but also in access to the rich body of scholarly literature produced in that region.

Following upon Jue Wang's article in the September 2006 issue of Serials Review entitled "Major Chinese Full-Text Electronic Information Resources for Researchers and Scholars" (32, no.3: 164-171), this issue of the Balance Point column invites readers of Serials Review to consider the perspectives of several journal editors from mainland China, Hong Kong, and Taiwan on the topic of adapting the popular notions of open access to Chinese publishing. Cataloging and reference librarian Xiaorong Shao examines various Chinese journal Web sites - two providing content through open access and four via subscription-based models - and talks with editors of the journals to see how they regard open access in relation to scholarly publishing in China in general and to their respective journals in particular. Are Chinese scholars 
and journal editors interested in providing their content to the world for free? Can some form of the open access model work within the Chinese economic and cultural context? We hope these informal interviews with Chinese journal editors in "The Balance Point" will contribute valuable dialogue to the further development of international cooperation in scholarly communication.

\section{Academic Journal Publishing in China}

For a better understanding of open access in China, it is useful to review the current state of journal publishing as it has existed for almost two centuries. Journal publishing accounts for one-third of the entire publishing industry in China.1 According to Xian Jia, academic journals published in China fall into five categories: multidisciplinary, natural sciences, technology, abstracts, and popular science. 2 The total number of academic journals (not including Hong Kong, Macao, and Taiwan) reached 4,876 in 2003 while in 1978 (the year China started reform and opening its economic and scientific exchange) there were fewer than 400 . The journals cover more than seventy subjects and are published in every province and municipality throughout China, with Beijing and Shanghai producing the most. One hundred and ninety-six of these are published in English and cover twenty-five subject areas.3

The sponsors for academic journals in China mainly derive from three sources - universities and colleges, academic associations, and research institutions - with the universities and colleges generating far more publications than the other two counterparts. There are approximately 600 universities and colleges in China.4 Normally, each university or college in China has at least one journal that publishes papers produced by its own faculty members and students. The comprehensive universities tend to publish several editions in different subject areas under one journal title to accommodate the needs of different reader groups. Social sciences (which usually include humanities and education), natural sciences, and engineering are three popular editions in the classification. To gain more specialized content than is possible in the university-wide journal, the colleges and the departments within the comprehensive universities have begun sponsoring journals. These sponsorships have made institutions of higher education the largest producers of academic journals in China.

Academic journals in mainland China are classified into three quality levels according to criteria established by the Library of Peking University.5 These three classes include authority journals, core journals, and regular journals. Journals not included in either the authority or core class are considered less prestigious. Another indication of the quality and prestige of a Chinese journal is to see if the journal has obtained a Chinese serial number (CN) and/or an International Standard Serial Number (ISSN). University journals generally start up without a serial number and are first distributed only within the affiliated institution. Once they receive serial numbers, journals can be distributed beyond the institution. Chinese university journals generally attract between 1,000 and 3,500 subscribers. 6 


\section{Role of Journal Editors and Peer Review}

Journal editors in China usually are employees of their affiliated institutions. Most editors are professionals or experts in the subject area of the journal. Traditionally, the journal editor was the only person who decided whether the submitted manuscripts were acceptable for publication. Biased and unjustified decisions were inevitable, as the editor's knowledge of the article's topic might be limited, especially in view of the rapid development in science and technology. In recent years, peer review has been introduced into Chinese academic journal publishing. Some journals utilize a hybrid system of peer review and editor selection, while others have adopted the peer review process entirely. Nevertheless, some journals still practice the traditional editor selection approach.

\section{Rationale and Journals Selected for Interviews}

Open access has gained increasing importance as a movement in European and American scholarly communication over the past ten years. In recent years, publishers and scholars in China have also started considering the possibility of opening access to their journals by making them freely available on the Web. Though calls for open access to China's scholarly literature have steadily increased, few concrete measures toward open access have been put into practice. But scholars both within and outside China suggest it is only a matter of time before many Chinese journals evolve into open access models.7 Currently only six journals published in mainland China appear in the Directory of Open Access Journals (DOAJ). 8 Because there are so few Chinese open access journals currently published, we chose to explore this topic by talking with editors from academic journals of both traditional subscription-based and open access models and published in different geographic locations of mainland China, Hong Kong, and Taiwan. We were interested in examining examples of journals from the three major sponsors of journals in China (universities, professional associations, and research institutions). Finally, we sought to talk with representatives from the journals to get their views on new developments in scholarly communication, particularly their views on open access publishing. Specifically, we posed the following questions: How do academic journal editors in China perceive the open access movement? What do they see as the advantages and disadvantages of their journals becoming open access? What are the challenges and problems facing their journal if it were to become open access, and how will this alternative publishing model affect the future of scholarly communication in China?

Eighteen journals were selected and the editors from the journals were contacted for informal interviews. Six editors - one from Taiwan, one from Hong Kong, and four from mainland China - agreed to discuss their journals. 9 Of the six journals considered, two are open access journals listed in DOAJ.10 Unfortunately, no one from the six open access journals in mainland China responded to our request for an interview (Table 1). 
Table 1. Chinese journals selected for interviews

\begin{tabular}{|l|l|l|l|}
\hline No. & Journal Title & $\begin{array}{l}\text { Economic } \\
\text { Model in } \\
\text { Use }\end{array}$ & Region of Origin \\
\hline 1 & Journal of Educational Media \& Library Sciences & Open access Taipei, Taiwan \\
\hline 2 & Journal of Sichuan International Studies University & Subscription Chongqing, \\
\hline 3 & Journal for Studies of Novels in the Ming and Qing Dynasties Subscription Nanjing, Jiangsu \\
\hline 4 & Journal of Science and Technology University of Suzhou & Subscription Suzhou, Jiangsu \\
\hline 5 & Journal of Chinese Verse Studies & Subscription Xiangtan, Hunan \\
\hline 6 & Asia-Pacific Forum on Science Learning and Teaching & Open access Hong Kong \\
\hline
\end{tabular}

The Interviews with Academic Journal Editors

\section{Journal of Educational Media \& Library Science}

The Journal of Educational Media \& Library Science (JoEMLS), an open access journal, is published by the Tamkang University Press (Taiwan) and co-published with the Department of Information \& Library Science and Chueh Sheng Memorial Library. It was formerly named the Journal of Educational Media Science (September 1980-June 1982) and before that it was called the Bulletin of Educational Media Science (March 1970-June 1980). The journal has appeared quarterly under the new title since September 1982. The journal is indexed or abstracted in several Chinese and international indexing and abstracting systems, as well as journal directories. The past issues are available at the journal's Web page.11

The Chief editor of JoEMLS, Dr. Jeong-yeou Chiu, is an associate professor in the Department of Information \& Library Science at the Tamkang University (Taiwan). One of his research interests is various systems of scholarly publishing. He is fully aware of the challenges faced in scholarly publishing and the conflicting interests among stakeholders in the European and American scholarly publishing industry. Dr. Chiu first saw open access as another platform to promote his journal. For that reason, he applied to DOAJ in 2005 for inclusion of his journal in the directory. In April 2006, all logistics were finalized, and JoEMLS was officially admitted to the DOAJ family. 
Participating in the DOAJ has not resulted in much extra work for the JoEMLS editorial staff, according to Dr. Chiu. The only DOAJ requirements that are mandatory are the format of the articles (e.g., including the titles and abstracts in English) and submission of the current issue URL to the DOAJ for link-up. Since the editorial staff began updating the online journal to meet the expectations of the DOAJ, the image of JoEMLS has greatly improved and has attracted more readers and authors.

Dr. Chiu found that the journal receives more manuscript submissions from Asian countries, such as India and Malaysia, but he is uncertain whether or not to attribute the increased submissions to exposure in the DOAJ since the journal is listed in several for-profit and nonprofit databases both domestically and abroad. As to the readership, Dr. Chiu believes that open access will attract more readers to the journal, but so far he has not seen any significant increase in this regard.

When asked how he anticipates open access changing scholarly communication between scholars in Taiwan and the rest of world in the future, Dr. Chiu points out that opinions on this topic vary widely throughout the scholarly community. He notes that one aspect of open access is as a strategy to counter the growing business consolidation in scholarly publishing. Since the threat of consolidation is not yet perceived as a problem in Taiwan and mainland China, the need for a counter strategy is not yet a concern in the region. However, Dr. Chiu is concerned that if open access publishing eventually dominates, the movement could seriously harm the commercial publishing system. There should be a balance, he said, between the benefits of both commercial and non-commercial publishing. If either of the two overly dominates the field, both authors and readers could suffer.

The best way for Chinese-language journals to be successful, Dr. Chiu suggests, is to improve their quality and attract more readers from abroad by encouraging high quality manuscript submissions. A popular practice today among Chinese scholars is to submit their high quality research papers to English-language journals abroad rather than to Chinese journals. Dr. Chiu is concerned about this practice and urges Chinese scholarly publishers to find ways to reverse the situation.

Dr. Chiu believes that open access is another platform for promoting scholarly information sharing and its emergence is an important milestone in scholarly communication. And though Chinese language scholarship does not face problems in serials cost inflation and academic publishing consolidation, the scholarly publishing battles emerging in the US and Europe serve as a warning to Chinese language journals for potential challenges in the future. 
Dr. Chiu suggests that an organization, such as that hosting the DOAJ, should become an authority for setting standards in the development of open access journals. They may need to formulate some uniform standards, such as standards for self-publishing (Fig. 1).

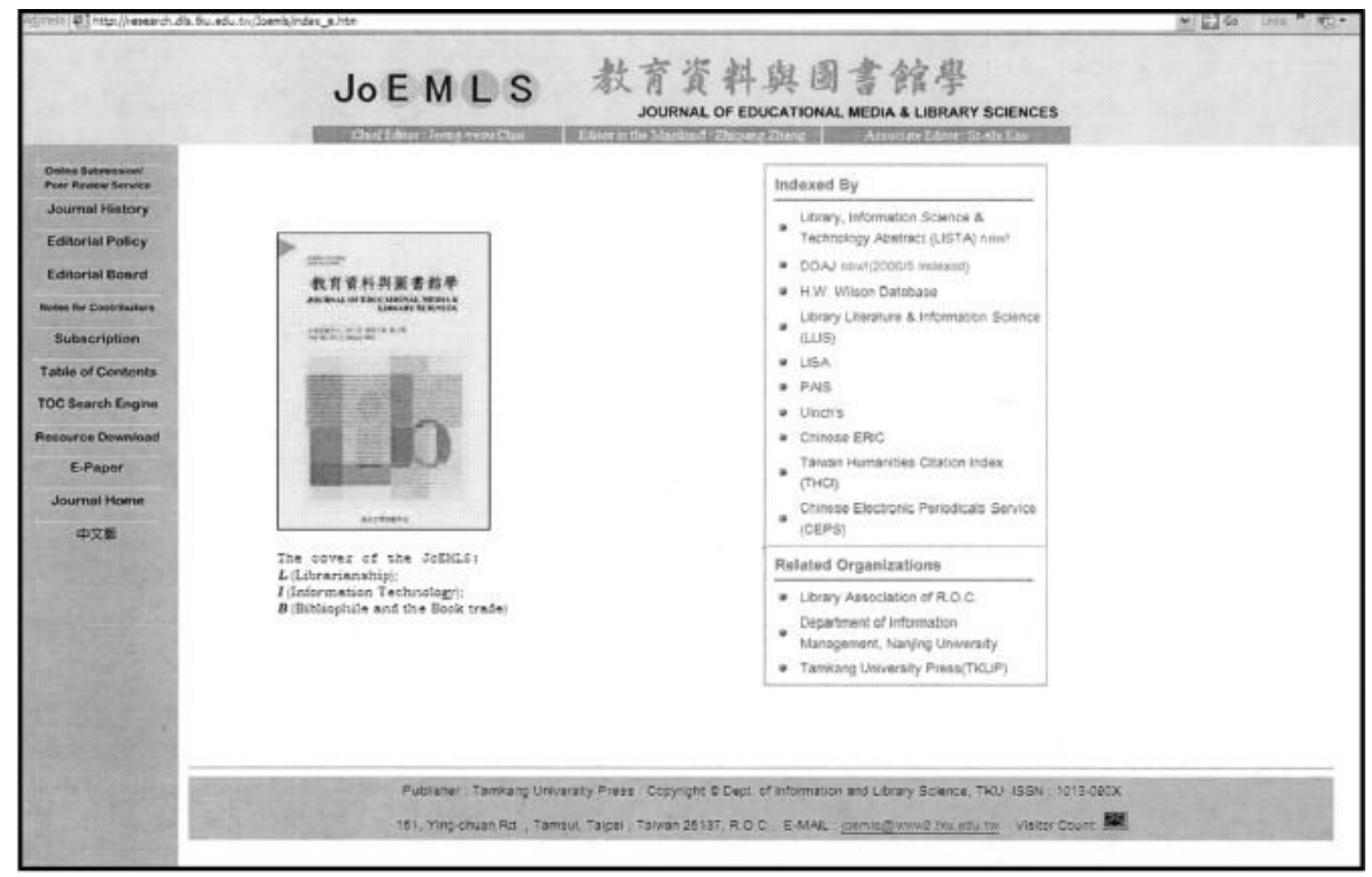

Figure 1. Journal of Educational Media \& Library Science.

\section{Journal of Sichuan International Studies University}

The Journal of Sichuan International Studies University (JSISU) is hosted by Sichuan International Studies University. It is the only journal publishing research papers in foreign language studies in southwest China. JSISU is a core journal and distributed both in China and abroad. The bimonthly journal publishes research results and new developments in teaching and learning in foreign literatures and languages, comparative literacy, and Chinese cultural studies. The abstracts of recommended articles from each issue are available on the journal's Web page.12 
Chief editor of JSISU, Professor Weiming Li, supports the idea of providing journals online and views this as a positive trend in journal publishing. However, he questions providing free access to the journals and suggests that a reasonable charge is justified. Like most university journals in China,JSISU has already been included in the China Journals Net (CJN), which is supported by the Chinese government that provides full-text access for a fee. He confirms that making the journal available online through CJN does offer more convenience and ease of use for some patrons, but he expresses concern that if all journals could be accessed freely online, few people would subscribe to the print counterparts.

Professor Li remains optimistic about the rapid expansion and development of university journals in China. He hopes that the application process for serial numbers will become easier and that more Chinese journals will be indexed in the Arts and Humanities Citation Index.

\section{Journal for Studies of Novels in the Ming and Qing Dynasties}

The Journal for Studies of Novels in the Ming and Qing Dynasties (SNMQD) was launched in 1985 and is published by the Social Sciences Academy of Jiangsu Province. This scholarly journal focuses on the research in novels from the Ming and Qing Dynasties in China. The journal is devoted to disseminating innovative studies and ideas about the Ming and Qing novels in both modern and ancient Chinese writing styles. This core journal is published quarterly both in print and electronically and is indexed in several Chinese indexing systems. SNMQD is available online on CJN, which, as noted earlier, charges readers for access to its content (but provides free access to the entire database for the journal's editorial staff). 13

When asked about open access, SNMQD chief editor, Xuejun Wang, a senior researcher in the Social Sciences Academy of Jiangsu, welcomes the idea of making journals freely available online, though he admits limited knowledge about open access at this time. Mr. Wang points out several challenges to making Chinese journals available online, whether for free or subscription. First, there is a shortage of technical staff to pursue electronic projects; there is only a sufficient number of staff to perform basic functions. Second, there is the problem of inadequate financial support. SNMQD is funded by its affiliated institution, and the funding generally is only enough to keep up with essential operating costs and the authors' remunerations. Budget constraints lead to a third challenge, the difficulty for the journal to purchase necessary equipment, such as high quality computers and software, to support an open access project. Fourth, there is the problem of Web space. Basically, the affiliated institution assigns Web space for basic information about SNMQD. The limited space is enough for only titles and abstracts to be posted. 
Although faced with these obstacles, Mr. Wang reiterates his support for open access, all the while conceding that it is a difficult initiative to implement in China. The editorial staff of most journals in China is driven by the bureaucracy of the system and by economic interests. An editorial team has little time to pursue much outside of a traditional agenda. Most journal editors may not even be aware of the open access movements in Europe and America, he added, much less, be ready to implement it.

Commenting on the future directions of academic journals in China, Mr. Wang lists problems that need to be resolved in Chinese academic journals. He describes an imbalance in journal publishing among different subject areas in terms of numbers published and quality of the content. Natural sciences and engineering, for example, produce more journals than the social sciences. Another example is the imbalance among the subjects addressed in the Englishlanguage journals of China. Of the 196 English-language journals published in China, 190 are in natural sciences with only six in social sciences.14 Beijing produces ninety-two Englishlanguage journals, while another fifteen provinces and three municipalities share the rest of the 104 titles. 15

Mr. Wang also indicates that journal management and quality control are shared responsibilities among different government organs. Various criteria and policies may be employed differently to assess similar kinds of journals and may lead to inconsistencies in how journals are classed. These inconsistencies, in turn, often cause confusion and inequity in how the journals are regarded in academia. Therefore, there is a tension between traditionally core journals and other journals. In addition, the journal distribution and subscription process is rigid and does not adequately accommodate the needs of the readers. Traditionally, journals are subscribed to through the postal service on an annual and biannual basis. If the reader misses a subscription deadline, it is difficult to subscribe at another time. Academic journals have fewer retail vendors than popular magazines and newspapers, so readers often have difficulty purchasing single issues of a journal. Mr. Wang concludes that unless these basic problems in journal publishing are resolved, academic journals in China will have difficulty moving forward with more innovative programs, such as online open access.

\section{Journal of Science and Technology University of Suzhou}

The Journal of Science and Technology University of Suzhou (JSTUSZ) is sponsored by the Science and Technology University of Suzhou, a comprehensive university that offers both undergraduate and graduate programs mainly in engineering, natural and social sciences. The Journal of Science and Technology University of Suzhou reflects the university's mission in teaching and research. The journal appears quarterly in three editions: engineering, natural sciences, and social sciences. The table of contents for each issue is available on the journal Web site.16 
The journal's editor Zhengliang Pang perceives open access publishing as a way of expanding the influence of a journal and as a mechanism for encouraging quality improvement. $\mathrm{He}$ elaborates that open access will certainly facilitate more outside readerships and manuscripts submission to his journal. Open access, he suggests, may present opportunities for the editorial staff to learn from other journals - opening opportunities for collaboration and resource sharing among journals in different regions both within and outside China.

Mr. Pang points out that the purpose of university journals is to serve as a medium for information exchange rather than as a source for profit. A university journal should be focused on improving the quality of its content and expanding its impact. Open access publishing provides an alternative means to achieve this latter goal. Mr. Pang does not see open access adversely affecting the subscription revenue of print counterparts, as there are still readers who prefer physical copies.

Mr. Pang's perspective about the problems and challenges of offering open access to his journal is similar to that of Mr. Wang. The challenges of converting a journal to open access center on issues related to personnel, equipment, technology, and the additional factor of time. It takes time, he says, for people to accept the concept of open access before adopting it.

Mr. Pang also responds specifically to the concerns that most university journals in China have low subscription numbers, poor quality, and extensive duplication in topics among the similar institutions. University journals have existed for a long time, and it is a tradition to have one for each college. He reveals that some scholars even suggest reducing the number of university journals by two-thirds as a starting point for quality improvement. With the movement toward consolidation of higher education institutions, he hopes that a mutual effort among institutions toward improving university journal publishing can be formulated. The only obstacle to this effort may be from prestigious universities that may not be willing to collaborate with less prestigious ones. A more viable solution may come from the professions and disciplines within each region.

Mr. Pang shares his journal's strategies for quality enhancement: JSTUSZ is focusing on the development of key articles and feature columns, as well as providing a monetary award for excellent manuscript submissions. According to Mr. Pang, the future of Chinese academic journals appears hopeful, and the possibilities are endless. With the development of new technologies, increased financial support, and new personnel entering academic publishing, interest in and feasibility of launching open access journals will steadily increase. The growth in international exchanges and collaboration will also be a driving force for the development of 
open access. Such international partnerships between university journals in China and abroad already exist.

\section{Journal of Chinese Verse Studies}

The Journal of Chinese Verse Studies (JCVS), sponsored by the Verse Association of China, is a subscription-based journal, hosted by Xiangtan University. The journal covers the study of different types of classic Chinese poetry, songs, and odes. The journal seeks to preserve Chinese cultural heritage, and at the same time, "make the past serve the present" through the promotion of both information exchange and study of classic Chinese literature among scholars. The journal has been published since 1987 and has produced thirty-eight issues to date on a quarterly basis. The table of contents of JCVS may be accessed from their Web site.17

Associate chief editor, Lian Xu, sees open access as a worldwide development trend in scholarly publishing. At present, important Chinese journals have been aggregated into large databases to achieve online accessibility in China. But viewers have to pay for full-text access to the databases. Generally, the journal itself only provides the indexing information, sometimes the first page and abstract on its own Web page. Mr. Xu admits that open access offers more convenience for users to search for and read articles, and it serves as a venue to promote the journal. But before open access can be implemented, issues around copyright and remuneration need to be clarified and problems with technology must be addressed. Finally, Mr. Xu notes that we have to consider the financial stability of traditional publishers whose work we value. Mr. Xu explains the difficulties his journal would face by offering open access. The full text of the JCVS has been included in Wan Fan and Qing Hua, the two important databases in China for online access. One difficulty is that although Xiangtan University has allocated Web space for the journal, the space is only used for posting the table of contents of each issue. The technological conditions for offering open access to the journal have just not yet developed. Like Mr. Wang and Mr. Pang, Mr. Xu notes that his current editorial staff is already overloaded with existing duties. No additional staff members are available to work on a special technical project such as open access and, in any case, no one currently on the editorial team has the expertise in Internet and related technology to pursue open access. As for the budget, each year Xiangtan University allocates the equivalent of approximately $\$ 10,000$ in operational funds for the journal. This is just sufficient to cover basic costs.

When asked his opinions about the advantages and disadvantages of offering open access, Mr. Xu expresses concern that open access could affect the future of aggregators if readers could view journal content freely online and that the quality of journals could be negatively impacted, causing a decrease in mail-order subscriptions. On the positive side, he admits that open access can expand the influence of a journal without much expense on promotion and advertisement. 
Finally, Mr. Xu acknowledges that academic journals in China have a lot of potential for development. Most journals in China currently must rely on government funding and therefore have to work around the challenges of bureaucracy. The rigid management system associated with that bureaucracy has made it difficult for journals to respond to changing market demands. Sooner or later, academic journals in China will have to face increasing challenges brought about by the evolving economy in China. They will soon have to critically examine their strategies if they are to learn to survive in a market environment. This includes spending more time on improving their product, employing multiple promotion strategies, and increasing subscriptions and access. With such measures, scholarly communication in China will prosper in a world that "allows a hundred flowers to blossom and a hundred schools of thought to contend."

\section{Asia-Pacific Forum on Science Learning and Teaching}

The Asia-Pacific Forum on Science Learning and Teaching (APFSLT) is an online periodical dedicated to effective learning and teaching of science in schools. It was launched by the Science Department of Hong Kong Institute of Education on July 10, 2000. APFSLT serves as an online publication channel for disseminating and sharing of new ideas, research findings, and innovative teaching methods in science education, as well as promoting academic exchange in using information technology for science teaching and learning.18 APFSLT is an English language, open access journal, listed in DOAJ.

When asked how APFSLT became an open access journal, chief editor of APFSLT, Dr. Yauyuen Yeung, explains that because of his past research experience in Web-based learning and his own specialty in science education, he was able to obtain an internal publication grant in 1999-2000 from his institution for launching a new online journal to be distributed free of charge to school teachers and educators. Sponsorships obtained from publishers and other sources have enabled the continuing release of new issues of this journal which totals fourteen issues to date. The aim of APFSLT is to reflect the vision of the Hong Kong Institute of Education, namely "optimizing each child's potential through the shared joy of learning and teaching," as well as fulfilling the mission of the Institute - to prepare and support teachers in professional development and to collaborate with schools on innovation and change in education.

Dr. Yeung finds open access to be beneficial to the APFSLT journal. Open access has enabled the journal to reach a larger number and wider spectrum of readership with little promotional or advertising costs. The reputation of the journal has grown rapidly, but he is concerned that there are still some people in academia with conservative views who question the quality of papers in such a journal. 
APFSLT has been a self-financing journal since inception. Dr. Yeung points out that an open access journal is much simpler to run and has lower operational costs than a print journal. He foresees open access allowing for new research findings and good professional practices to become more easily and widely disseminated to teachers and researchers who generally do not have easy access to academic journals. Dr. Yeung also predicts that open access will develop into a major publishing phenomenon, evidenced by the ever increasing amount of online publishing that is emerging in many academic fields (Fig. 2).

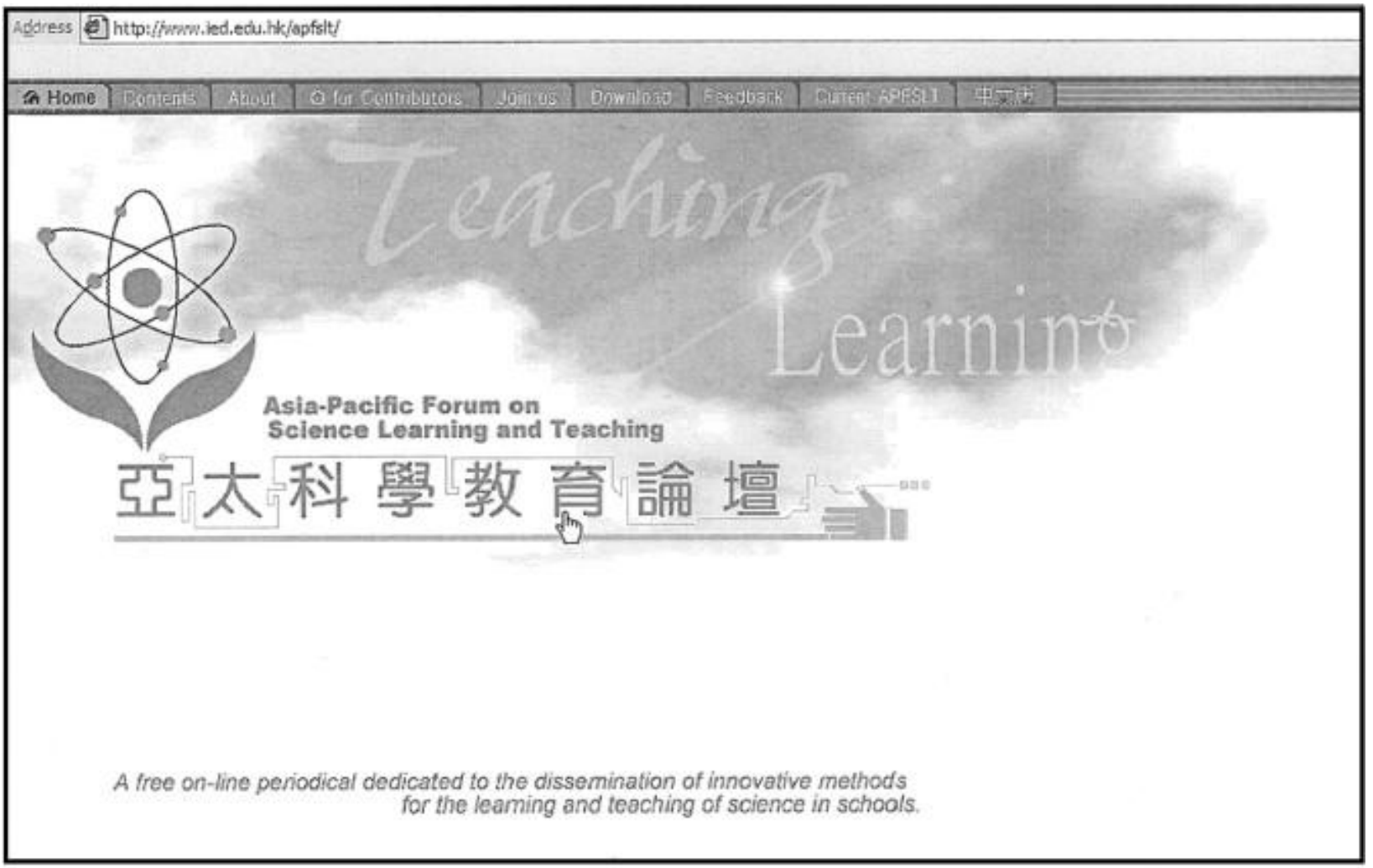

Figure 2. Asia-Pacific Forum on Science Learning and Teaching.

\section{Conclusions}

The journal editors interviewed for this column foresee some positive potential of open access. They acknowledge that open access is a means of maximizing access to the academic 
literature and expanding the impact of academic journals. They also share the belief that open access can help academic journals to become more internationally oriented and to publish more in accord with international standards. The editors also appear to agree that open access is a trend that will continue in scholarly publishing and that sooner or later publishers in China will have to deal with it.

The editors of subscription-based journals in mainland China interviewed express more concern about funding, technology, personnel, and policy related to pursuing open access, while the open access journal editors in Hong Kong and Taiwan do not perceive these issues as major problems for them. Resistance to change from the status quo in scholarly publishing and the fear of possibly losing revenue caused by open access are continual concerns with some of the editors.

Editors we talked with from mainland China also noticed several problems with their current system of journal publishing. A rigid management, a single subscription and distribution process, and an environment that does not encourage more quality improvement are seen as major hindrances to the development of academic journals in China.

Finally, an interesting conclusion comes from the interview with Dr. Chiu of the JoEMLS: since open access relies on the Internet, those who have access will become information rich, and those who do not will become information poor. Widespread use of online resources, including open access, could create this imbalance, especially in developing countries such as China, where a vast population still has very limited access to computers. Conceivably, the ideal for scholarly publishing in China, therefore, would be a co-existence of print and online journals with a mix of both open and paid access.

\section{Acknowledgment}

The author wishes to acknowledge Dr. Zhao Xinggen, a professor in Suzhou University in China and a visiting scholar in the Department of Foreign Languages and Literatures at Appalachian State University, for his insights into publishing and open access in China from the perspective of a reviewer for several Chinese university journals. His help with contacting the editors for interview is also greatly appreciated.

\section{References}

1. Fang Liu and Xianghui Wu, "Comparing of Three Kinds of Print, Electronic and Online Academic Journals [In Chinese]", Library Development 5 (2002), pp. 45-48. 
2. Xian Jia, "The Past, Present and Future of Scientific and Technical Journals of China", Learned Publishing 19 (2) (April 2006), pp. 133-141.

3. Ibid, 136.

4. Ibid.

5. Xinggen Zhao, personal communication (2006).

6. Ibid.

7. Richard Poynder, "Open and Shut?", China Mulls Open Access (2006) http://poynder.blogspot.com/2005/10/china-mulls-open-access.html (accessed November 16, 2006).

8. Conghui Fang and Xiaochun Zhu, "The Open Access Movement in China", Interlending and Document Supply 34 (4) (2006), pp. 186-193.

9. In China, the family name precedes the given name. To avoid confusion for western readers, this paper has followed the English convention in arranging the order of names.

10. Directory of Open Access Journals, http://www.DOAJ.org (accessed November 16, 2006).

11. Information about The Journal of Educational Media and Library Science was obtained from an interview with the chief editor, Dr. Jeong-yeou Chiu, and the Web site at http://research.dils.tku.edu.tw/Joemls/index_e.htm (accessed November 16, 2006).

12. Information about The Journal of Sichuan International Studies University was obtained from an interview with the chief editor, Professor Weiming $\mathrm{Li}$, and the Web site at http://www.sisu.edu.cn/office/xb/index.htm (accessed November 16, 2006).

13. Information about The Journal for Studies of Novels in Ming and Qing Dynasties was obtained from an interview with the chief editor, Xuejun Wang, and the Web site at http://www.jsass.com.cn/jieshao/xskw_4.htm (accessed November 16, 2006).

14. Yuehong Zhang, Changdong Lin, Jiang Li and Sen Wang, "How Many English Language Academic Journals Are Published in China?" [In Chinese], Chinese Journal of Scientific and Technical Periodical 14 (2) (2003), pp. 148-152.

15. Jia, "The Past" 136.

16. Information about The Journal of Science and Technology University of Suzhou was obtained from an interview with the editor Zhengliang Pang and the Web site at http://unit.usts.edu.cn/xb/ (accessed November 16, 2006).

17. Information about The Journal of Chinese Verse Studies was obtained from an interview with the associate chief editor, Lian Xu and the Web site at http://web.xtu.edu.cn:8081/qks/dzqk.htm (accessed November 16, 2006). 
18. Information about The Asia-Pacific Forum on Science Learning and Teaching was obtained from an interview with the chief editor Dr. Yau Yuen Yeung and the Web site at http://www.ied.edu.hk/apfslt/ (accessed November 16, 2006). 